\title{
A REPRESENTAÇÃO DO VIVER NO CAMPO: O ESTEREÓTIPO DO HOMEM E DO ESPAÇO RURAL NA TELEVISÃO
}




\title{
A REPRESENTAÇÃO DO VIVER NO CAMPO: O ESTEREÓTIPO DO HOMEM E DO ESPAÇO RURAL NA TELEVISÃO
}

Resumo:

Busca-se articular os conceitos estereótipos e representações com o objeto homem do campo e o espaço rural em que ele vive e trabalha através da utilização de exemplos encontrados em telenovelas brasileiras. Utiliza-se a história de vida de uma trabalhadora do Feirão Colonial, que reúne pessoas envolvidas com a agricultura familiar, para trabalhar com a questão da assistência da telenovela e a representação e o estereótipo do morador do campo e seu espaço de vivência.

Palavras chave: Representações midiáticas; Telenovela; Estereótipos; Trajetória de Vida

THE REPRESENTATION OF LIVING IN THE FIELD: THE STEREOTYPE OF MAN AND THE RURAL AREA ON TELEVISION

\begin{abstract}
:
It seeks to articulate the concepts stereotypes and representation with the object man of the field and the rural area where he lives and works through the use of examples found in Brazilian soap operas. Using a life history of a worker of Feirão Colonial, that brings together people involved to family farming, to work with the question of soap opera assistance and the representation and the stereotype of the resident of the field and his space experiences.
\end{abstract}

Keywords: Media representations; Soap opera; Stereotypes; Life trajectory

\section{LA REPRESENTACIÓN DEL VIVIR EN CAMPO: ESTEREOTIPO DEL HOMBRE Y DEL ESPACIO RURAL EN LA TELEVISIÓN}

Resumen:

Buscase articular los conceptos estereotipos y representaciones con el objeto hombre del campo y el espacio rural en que él vive y trabaja por medio de la utilización de ejemplos encontrados en telenovelas brasileñas. Utilizase la historia de ida de una trabajadora do Feirão Colonial, que reúne personas involucradas con la agricultura familiar, para trabajar con la cuestión de la asistencia de la telenovela y la representación y el estereotipo del morador del campo y su espacio de vivencia.

Palabras Clave: Representaciones mediáticas; Telenovela; Estereotipos; Trayectoria de vida 


\section{INTRODUÇÃO}

O artigo busca refletir sobre estereótipos, representações culturais e práticas significantes, categorias de análise presentes no trabalho de Stuart Hall, assim como busca trabalhar o conceito representação social utilizado por Vera França. Nossa proposta é apresentar articulações teóricas iniciais sobre as modificações conceituais sobre o campo e a cidade, a representação do homem do campo na televisão brasileira, o estereótipo acerca seu modo de vida e também sobre o espaço rural em que vive.

O estereótipo do homem do campo no Brasil está presente antes da invenção da televisão e foi reproduzido no imaginário brasileiro, como em Jeca Tatu, personagem da literatura. Jeca Tatu é um caipira do interior paulista criado por Monteiro Lobato. Ele é preguiçoso, avesso à higiene pessoal, não usa calçado, é pobre e com pouco estudo. Após a televisão se consolidar como um importante meio de comunicação de massa no país, o imaginário do caipira permaneceu, e outras representações do homem do campo, assim como de sua sociabilidade e do mundo rural, foram reproduzidos.

Um resgate possível da representação que pesquisamos é nas telenovelas brasileiras, já que os melodramas e o imaginário brasileiro são linhas entrecruzadas. Um exemplo é Julião Petrúchio, personagem presente na adaptação para a televisão da obra A Megera Domada de Shakespeare para a teledramaturgia, "O cravo e a Rosa". Julião é um homem rude e ignorante, "mas com bom coração" "Vive no campo, come com indelicadeza e não apresenta etiquetas que são bem vistas aos olhos das pessoas mais ricas e que vivem na cidade.

A hipótese da qual partimos é a de que os produtos televisivos apresentam uma representação homogênea sobre a vida no campo, assim como um preconceito lingüístico, em especial das classes populares que trabalham com agricultura familiar. A representação midiática do espaço rural em telenovelas, por exemplo, é de um espaço atrasado, de um mundo estático onde há poucos acontecimentos. O urbano seria o local de progresso e onde as "coisas realmente acontecem", do movimento e das possibilidades de ascensão social. O campo somente seria o "locus de progresso" caso fosse atrelado ao mercado de exportação, como latifúndios, grandes lavouras ou produção pecuária de corte.

Na maioria dos produtos televisivos há o estereótipo de que os trabaIhadores ou as pessoas que vivem em zonas rurais são ingênuos. A distância para chegar a uma escola, a falta de transporte e a dificuldade em permanecer estudando faz com que o capital escolar seja mais difícil de ser alcançado. Sua 1 Cravo e a Rosa foi uma telenovela brasileira produzida e exibida no horário entre as 18 horas e 19 horas pela Rede Globo de junho de 2000 a março de 2001. Escrita por Walcyr Carrasco e Mário Teixeira.

2Retirado do site Memória Globo. Disponível em: <http://memoriaglobo.globo.com/Memoriaglobo/0,27723,GYNo-5273-236417,00.html > Acesso em: 21/06/2011 
fala é diferente da pessoa urbana e, muitas vezes, a televisão a mostra como inculta. Além disso, mostra o padrão da língua portuguesa como superior, dando privilégio a uma classe social que teve acesso à escola (ALCKMIN 2004). Em várias situações, quando o morador do meio rural vai à "cidade grande", sua procedência é logo percebida, sua fala é distinta, seus "erres" são carregados e os verbos são conjugados de forma "caipira". Não raro sofre, assim, discriminação sociolingüística.

Através de uma entrevista em profundidade e semi-aberta (DUARTE, 2006) com Maria3, 20 anos, proveniente da localidade de Pinhal Grande (RS), buscamos compreender de que forma essa jovem proveniente do meio rural interpreta como a televisão apresenta o mundo em que ela cresceu, ou seja, o mundo rural ${ }^{4}$. Foram mostrados fragmentos de telenovelas onde estão presentes trabalhadores rurais como bóias-frias, agricultores e fazendeiros, assim como homens e mulheres que vivem no campo.

\section{A MEDIAÇÃO DO HOMEM: A REPRESENTAÇÃO SOCIAL}

Em um momento em que os estudos de comunicação se expandem e buscam sua consolidação, conceitos como representação social e mediações ganham particular importância (FRANÇA, 2004). A pesquisadora Vera França aproximou em diversos momentos esses conceitos para discursar e pensar a própria concepção de comunicação. Neste primeiro trabalho pretendemos trabalhar com o conceito de representação social.

Representação social é um conceito utilizado por vários campos de saberes, como psicologia, sociologia e semiótica. Representação significa, em poucas palavras, o que forma conteúdo concreto de um ato de pensar e que é passível de transformação, ou seja, a representação está inserida no campo histórico e inter-relacionado aos processos de construção e lutas de poder. Os meios de comunicação são, assim, espaços de construção e veiculação das representações sociais, essas mediações entre sujeitos com intersubjetividades. Eles são os canais de mediação no mundo contemporâneo, agindo no significante, seja na fala, escritura, imprensa, vídeo, filme ou gravações.

A cultura está relacionada aos significados partilhados com a linguagem e, junto à ela, dá sentido e constrói significados. A linguagem, para Hall (1987), é um sistema de representação e com ela os indivíduos interpretam o mundo de forma compartilhada, entretanto com lugar às suas especificidades e às suas leituras com referência ao seu capital simbólico, à sua classe social e ao seu lugar de fala. Partimos do pressuposto de que o sujeito histórico e o homem estão engendrados entre si, ou seja, o indivíduo é produtor da realidade

3Nome fictício e escolhido pela entrevistada.

4Não tratamos aqui o mundo rural separado do mundo urbano, como se fossem esferas diferentes, sem conexões. 
e produto, também, da esfera coletiva.

Não sendo palpável, a cultura não se encontra nas páginas de um livro ou na sonoridade de uma música. Cultura é a prática e o processo que o indivíduo faz com a apropriação da leitura e no ato de escutar esses bens simbólicos musicais. Assim, o significado sempre está atrelado à prática social e à forma como representamos os sistemas de significados. Logo, quando se diz que certo indivíduo não tem cultura, ou que o homem do campo é ignorante, deve-se analisar que a cultura não é um bem adquirível, como ao comprar um CD, e sim ao se apropriar dos variados bens simbólicos existentes nas esferas diversas da sociedade.

A representação se dá a partir da leitura e da interpretação e está, assim, ligada diretamente à linguagem. Dentro do debate da representação do homem que vive no campo na televisão brasileira, a tradução realizada pelos indivíduos seria o significado em constante disputa. O significado, então, não está livre da disputa e da negociação das relações de poder da sociedade. Muitas vezes, e normalmente assim o são, os significados são binários, como cidade/ campo, rural/urbano, "cidade grande"|"pra fora", e "grosso"|"com modos", latifundiário/pequeno agricultor. Por vezes os significados podem ser bastante complexos como "herdei as terras do meu pai"|"vim pro MST pra lutar pela minha terra via reforma agrária". As representações são produtos dos contextos sociais, não podendo ser analisadas sem a historicização:

Elas são produzidas no bojo dos processos sociais, espelhando diferenças e movimentos da sociedade; por outro lado, enquanto sentidos construídos e cristalizados, elas dinamizam e condicionam determinadas práticas sociais. Na sua natureza de produção humana e social, têm uma dimensão interna e externa aos indivíduos, que percebem e são afetados pelas imagens (passam por processos de percepção e afecção) - e, desses processos, as devolvem ao mundo na forma de representações. (FRANÇA, 2004, p.19)

\section{OS CONCEITOS E SUAS REPRESENTAÇÕES}

Hall (1987) afirma que os próprios conceitos são representações mentais das coisas do mundo. Os mapas conceituais são significados compartilhados por pessoas com formações culturais convergentes. Assim, os conceitos de campo e cidade se tornam representações relacionadas a algumas materialidades e simbolismos. Williams (1989, p.11), que estudou o campo e a cidade na literatura inglesa ao longo dos séculos, afirma que essas palavras representam muito nas vivências das comunidades:

Em torno das comunidades existentes, historicamente bastante variadas, cristalizam-se e generalizam-se atitudes emocionais poderosas. O campo passou a ser associado a 
uma forma natural de vida-de-paz, inocência e virtude simples. À cidade associou-se a idéia de centro de realizações - de saber, comunicações, luz.

Percebe-se que pessoas que foram morar no campo no Brasil, especialmente após 1980, não o fizeram somente para trabalhar com animais ou plantar. Há uma crescente exploração do agroturismo e de turismo de aventura, como trilhas ecológicas. O campo, assim, também se tornou um local de consumo para aqueles que sempre habitaram a cidade e que por diversos motivos, a fuga do trânsito, da violência ou a escolha de uma vida alternativa, migraram para o campo. Esses autores (BERNARDELLI, 2006) enfatizam as inovações que ocorreram no campo nas últimas décadas, afirmando que não se devem vincular os espaços rurais à ausência de serviços, de cidadania e ao atraso.

Discute-se que atualmente há novas configurações no espaço rural, onde o campo não seria somente o lócus de produção primária, como pecuária e agricultura, especialmente em decorrência da crescente urbanização. Há a discussão (ENDLICH, 2006) de que a urbanidade tenderia a apagar as distinções entre o campo e a cidade, no entanto, não se pode negar a existência de ilhas de ruralidade e de questões mais profundas, como simbólicas e estruturais, onde a relação entre a cidade e o campo se aprofundam.

A reflexão sobre os binômios campo/cidade e rural/urbano é um ponto forte de discussão em diversas perspectivas. Alguns autores falam da urbanização como uma via de mão única, como se a cidade fosse o centro irradiador e que o urbano seria o fim, também, do próprio rural. Outros autores (SOBARZO, 2006) afirmam que o campo tem importância fundamental, pois através de suas demandas há determinação de processos na cidade.

Uma das principais críticas que se faz é em referência ao Decreto - Lei 311 do ano de 1938 que definiu o que é cidade no Brasil. De acordo com os críticos, em especial Veiga (2002), o conceito foi puramente formal e não estava de acordo com a realidade brasileira. Veiga utiliza rural como sinônimo de campo e urbano como sinônimo de cidade e criou o conceito de "rurbano" para explicar o que ocorre na maioria das cidades brasileiras: em sua concepção, o Brasil é muito menos urbano do que mostram as estatísticas.

\section{O CAMPO E A CIDADE, O AGRICULTOR E A CIDADE: A QUESTÃO DO ESTEREÓTIPO}

A diferença é importante no estudo das representações, especialmente porque a prática da representação da diferença na cultura é interligada ao estereótipo. Estereótipos são citados por Lippmann em sua obra prima 'Opinião Pública" (1922) como a mediação entre a realidade com o público. O estereótipo naturaliza o que já existe na sociedade e esconde o cultural. $O$ indivíduo acaba utilizando-se de estereótipos ou de representações coletivas para se co- 
municar com seus pares.

Quando a diferença, que não deve ser tratada de forma natural e como essência (SILVA, 2000), é retratada em oposições binárias, há uma especial implicação de atitudes e sentimentos. A naturalização da diferença, assim, é uma estratégica representacional. Por exemplo, a prática de reduzir as práticas simbólicas do homem do campo e de sua vivência cotidiana a uma representação pacata, sem lazer e sem política. Quando há um movimento social que organiza esses trabalhadores rurais por uma transformação na ordem da estrutura fundiária, ou seja, reivindicando a reforma agrária, há um conflito. O homem do campo, o colono, o peão e o bóia-fria não são mais inseridos nas posições que antes ocupavam. Eles fogem da normalidade, viram "anarquistas" e "baderneiros". Hall (1987) explica que estereótipos existem onde há grandes desigualdades de poder e onde há, como conseqüência, construção do outro. Esse é um dos casos. Maria tem 20 anos e, antes de conseguir uma bolsa de estudos para cursar o Ensino Superior há três anos, sempre morou na região rural de Pinhal Grande (RS), município de 4 mil habitantes e vizinho de um dos mais antigos assentamentos do MST do estado - Nova Ramada. A família de Maria é formada por pequenos agricultores e seus primos e tios continuam a se sustentar com a agricultura familiar. Entretanto, como lembra Williams (1989, p.19) "a vida do campo e da cidade é móvel e presente: move-se ao longo do tempo, através da história de uma família. " Assim, Maria que nunca gostou das lidas campesinas, decidiu estudar na "cidade grande".

Embora tenha decidido abandonar a pequena propriedade dos pais, Maria diz ter aproveitado o que a vida no campo lhe proporcionou. Questionada sobre a vida no campo ser tranqüila, Maria diz que para ela foi ao contrário, pois tinha sempre o que fazer, seja na propriedade da família, seja em Pinhal Grande, "especialmente nos finais de semana, na praça". A filha de agricultores reclama da falta de opções para os jovens em Santa Maria e da individualidade da "cidade grande".

A estudante de Serviço Social acredita que os moradores do interior de Pinhal Grande puxavam bastante o "erre". Na escola do município, onde os citadinos e os campesinos se encontravam, o sotaque carregado era motivo de chalaça. Maria, que não tem parentesco italiano e não puxa o "erre", embora morasse no interior, também ria, "porque achava estranho e diferente, como na fala carroça, eles falavam caroça”. Em todas as comunidades, por menores que sejam, como em Pinhal Grande, existem variações lingüísticas. Alkmin (2004) diz que essas variedades são consideradas superiores e inferiores, dependendo do número de falantes e da posição social do enunciador. Logo, há indivíduos, e não só pertencentes de distintas classes sociais ou de diferentes lócus territoriais, que ficam com mais prestígios, como se falassem a língua portuguesa mais culta. Há, assim, normas estabelecidas pela estrutura sociopolítica da comunidade.

Foram selecionadas quatro partes de telenovelas já conhecidas por Ma- 
ria, como "O Cravo e a Rosa", "O Rei do Gado" e "Malhação". As partes selecionadas versavam sobre o homem caipira, ingênuo, que fala errado e se veste mal, caso de Julião Petrúchio de "O Cravo e a Rosa". No caso de "Malhação", a assistência foi de cenas com a personagem de Marcinha, cowgirl que usava gírias do interior de São Paulo e portava roupas comuns em festas de rodeio. $O$ último caso, a telenovela "O Rei do Gado", mostrou um bem sucedido fazendeiro.

Os pais de Maria têm 40 hectares, o que os caracterizam como classe média baixa. Para ela, fazendeiro são aqueles que têm 'terras a mais, é poderoso, se acha, produz soja, monocultura, usa tecnologia e tem recurso". A representação televisiva do fazendeiro costuma ser bem mais comedida, sua fala é mais rebuscada e sua personagem não é pejorativa e caricata.

Aproveita-se a telenovela de 1996 "O Rei do Gado" para falar sobre a questão do MST. Maria, que morou até os 17 anos no município vizinho de alguns dos mais antigos assentamentos da reforma agrária do país, demonstra ter um discurso híbrido. Em alguns momentos desconhece a funcionalidade do movimento social, mas afirma que no Brasil "poucos têm muito e muitos têm pouco". Maria diz que os assentamentos vizinhos à Pinhal Grande produzem corretamente e são bem organizados. Entretanto faz críticas a algumas pessoas pobres que moram na cidade e que decidiram ingressar no MST para conquistar um lote de terra. Para ela, os "da cidade não sabem lidar com a terra".

Embora tenha crescido no campo e atualmente trabalhe todos os finais de semana no Feirão Colonial, onde ajuda os familiares a comercializar feijão, mandioca e pinhão, Maria não pretende retornar ao campo. Quando lhe é perguntado o que pensa sobre a cidade, a estudante responde "desenvolvimento, lugar que centraliza as coisas, onde tem recursos, penso em pobreza e pouco emprego". Relacionada ao campo, Maria adere às falas dos citadinos, pois pensa que "no campo não vai ter preocupação, vai ser descanso, vou estar longe do vai-e-vem". Williams (1989) explica que à cidade se constituíram poderosas associações negativas, como lugar de barulho, individualidade, competitividade e ambição.

Maria gostaria de ver uma imagem diferente do campo na telenovela:

\footnotetext{
'Eu gostaria que a novela mostrasse o campo como ele é, uma forma de trabalho, pois as pessoas sobrevivem do campo, no campo também se tem lazer e divertimento. Às vezes parece que passam a noção de que no campo são tudo uns miseráveis, uns desinformados."
}

\section{CONSIDERAÇÕES}

O campo e a cidade, em alguns aspectos, são territórios distintos e devem ter políticas públicas relacionais. Entretanto, em vários momentos, as territorialidades estão em inter-relação, salvo algumas ilhas de ruralidade que se 
mantêm isoladas - e até esse isolamento pode ser questionado, seja pelo crescimento do alcance das telecomunicações e das rotas de transporte. Campo e cidade e suas fronteiras culturais estão, assim, em sua maioria, articulados.

Os estereótipos do campesino e do meio em que ele vive não surgiram na telenovela brasileira, mas atualmente a televisão é um dos principais meios de comunicação de massa. Isso faz com que seus personagens, seus trejeitos e modos de falar reafirmem estereótipos. Além disso, como afirma Hall (1987), a representação normalmente é um olhar do outro sobre um grupo, especialmente numa situação de relação de poder. Embora a telenovela represente a classe popular camponesa, seus representantes não estão em condição de escolha.

\section{REFERÊNCIAS}

ALKMIM, T. M. Sociolingüística. Parte I. In: MUSSALIM, F., BENTES, A. C. (orgs.) Introdução à lingüística: domínios e fronteiras. 4. ed. São Paulo: Cortez, 2004. v.1.

BERNARDELLI, Maria Lúcia. Contribuição ao debate sobre o urbano e o rural. In: SPOSITO, Maria Encarnação e WHITACKER, Arthur (orgs). Cidade e Campo: Relações e Contradições entre Urbano e Rural. $1^{\mathrm{a}}$ edição. São Paulo: Expressão Rural, 2006.

DUARTE, Jorge e BARROS, Antônio. Métodos e técnicas de pesquisa em comunicação. São Paulo: Atlas, 2006.

ENDLICH, Ângela Maria. Perspectivas sobre o urbano e o rural. In: SPOSITO, Maria Encarnação e WHITACKER, Arthur (orgs). Cidade e Campo: Relações e Contradições entre Urbano e Rural. $1^{a}$ edição. São Paulo: Expressão Rural, 2006.

FRANÇA, Vera Regina Veiga. Representações, mediações e práticas comunicativas. In: PEREIRA, Miguel; GOMES, Renato Cordeiro; FIGUEIREDO, Vera Lúcia Follain de. Comunicação, representação e práticas sociais. v. 1. Rio de Janeiro: PUC Rio; Aparecida: Idéias \& Letras, 2004.

HALL, Stuart. Representation: Cultural Representations and Signifying Practices. London, 1987.

SILVA, Tomaz Tadeu da (org). Identidade e Diferença. Petrópolis, RJ: Vozes, 2000. SILVEIRA, Célia Regina da. A Epopéia do Caipira: regionalismo e identidade nacional em Valdomiro Silveira. UNESP - Universidade Estadual Paulista, Assis, 1997. (Dissertação de mestrado) apresentada ao Programa de Pós-Graduação em História da Faculdade de Ciências e Letras da Universidade Estadual Paulista "Júlio de Mesquita Filho", Campus de Assis, 1997. SOBARZO, Oscar. O urbano e o rural em Henri Lebebvre In: SPOSITO, Maria Encarnação e WHITACKER, Arthur (orgs). Cidade e Campo: Relações e Contradições entre Urbano e Rural. São Paulo: Expressão Rural, 2006.

VEIGA, José Eli da. Cidades imaginárias: o Brasil é menos urbano do que se calcula. Campinas: Autores Associados, 2002.

WILLIAMS, Raymond. O Campo e a Cidade. São Paulo: Editora Schwarcz, 1989. 


\section{Júlia Schnorr}

Mestranda em Comunicação Midiática (UFSM - Bolsista REUNI/ (APES). Formada em Licenciatura e Bacharelado em História (UFSM). Acadêmica do curso de Jornalismo (UFSM). Foi bolsista de Iniciação Científica do PIBIC/CNPq, do PROLICEN/UFSM e PROBIC/UNIFRA. Participou do Coletivo Práxis de Educação Popular e atualmente faz parte da Oficina de Vídeo TV OVO, também Ponto de Cultura Espelho da Comunidade. 